\title{
Mine closure groundwater pollution prevention and control technologies and development trend
}

\author{
Song Luan \\ School of Environmental and Engineering, \\ Guilin University of Technology, \\ Guilin,541000,China \\ E-mail:512129393@qq.com \\ Fa-Wang Zhang and Yan-Zhen Hao \\ Institute of Karst Geology, Chinese Academy of Geological Sciences, \\ Guilin, 541000, China \\ E-mail:zhangfawang@karst.ac.cn
}

\begin{abstract}
In recent years, China sees an increasing number of mine closures year by year with the continued exploitation of resources in many regions in China, and it is followed by some groundwater pollution and environmental problems caused by mine closures. This paper studies a series of Hydrogeological effects caused by mine closures, pollution principles and disasters easily induced by mine closures; it primarily analyzes mine closure treatment and prevention measures, summarizes some practical ways and methods to the protection of groundwater resources in conjunction with the prevention technologies and lessons at home and abroad, and it gives some recommendations on the future development trend.
\end{abstract}

Keywords: Mine Closure;Cross Strata Pollution; Underground Water Pollution Prevention and Control Technologies; Development Trend.

\section{Introduction}

China is a major mining country with a long history of exploitation of mineral resources. As a result of the continuous exploitation of resources, resources are exhausted in many regions of China and the mines are undergoing or in the face of reorganization, planning or even shutdown. Taking coal mines as an example, China plans to close more than 2000 small coal mines with an annual production below 90,000 tons at the end of 2015. Along with the annually increasing number of mine closures, the underground water destruction and pollution and other hydrology and environmental problems brought out by mine closures have become increasingly apparent. On one hand, drainage stops and water begins to collect as mines are closed, the problems, such as rising water level, changes in 
occurrence conditions, gradual acidification of water, rising salinity and heavy metal outside the permitted range, are emerging, and pollutions will occur in wide area once the contaminated water is connected with the Ordovician limestone aquifer; on the other hand, mining activities and various emergent disasters in mines (gas explosion and impact earth pressure) cause rock body collapse and significant displacement, fracture opening and fault activation, which provide hydraulic contacts for groundwater pollution[1]. After a mine is closed or abandoned, mine dewatering and drainage stop, underground water levels rise and groundwater recharge to the mining space, easily leading to geological and hydrological disasters and environmental damages, such as surface collapse and subsidence, surface water and underground water pollution, drainage inrush in adjacent mines and poisonous gas escape[2]. The immediate monitoring, treatment and research of hydrology and water of mine closures plays an important role in the protection and human proper use of groundwater resource and sustainable economic development.

\section{Hydrogeological Characteristics of Mine Closure Area}

\subsection{Hydrogeological effects caused by mining activities}

Hydrogeological effects mean the changes in hydrogeological conditions in mining areas caused by coal mining, which are firstly conceptualized and studied abroad. The exploitation of resources causes the changes in water quality and quantity and the impacts on local ecosystems, mainly including the following four aspects:

(1) Changes in groundwater input and output conditions: for input conditions, funnels caused by dewatering and drainage change the size of recharging area and resource extraction leads to the connection of underground water and surface water and thus increases supplement. For output conditions, groundwater is discharged through spring discharge and effusion discharge before mining while artificial discharge after mining.

(2) Changes in aqueous media: the water-flowing structures, such as mine tunnels, gob areas, some faults and collapse pillars, become the main areas for groundwater discharge, accompanied by the formation and evolution of caving zones and fracture zones. Roof rock mass of a mine plays a transmission role due to its water retention capacity or relative impermeability. The damages and disturbances of mining activities to rocks cause more aqueous fractures and the connection of new aqueous spaces.

(3) Changes in groundwater flow fields: the mining activities expose and connect several aquifers and damage the balanced groundwater system, complicate groundwater hydrodynamics fields, lead to the difference in the 
water head values of surface water, phreatic water and confined water and thus to the alterations of groundwater flow fields[3].

The hydrogenlogical effects produced by mines involve a dynamic system. With the constant progress in mining activities, border, input and output conditions of the mine groundwater system are undergoing constantly changes, and some hydrogenlogical effects are contributory to the formation of mine groundwater system and effect its evolution direction and speed, and the newly-developed mine groundwater system induces new hydrogenlogical effects, causing a process of constant feedbacks and circulations. So as soon as one of the links of hydrogeological effects changes, measures shall be promptly taken to prevent it from further inducing the evolution of other links or even the entire system.

\subsection{Principles of groundwater pollution in mining areas}

Mine closure pollution is mainly caused by cross strata pollution, which is a process that the water level in gob area rises above the concealed karst water level after a coal mine is closed and the water recharges the concealed karst water through the connecting parts. It falls into two categories by runoff direction of sewage [4]. The first is shown in Figure 1. As a coal mine is closed, when mine level rises above the miming floor confined water head at the high water level, the water of the contaminated shallow aquifers will go downwards and pollute floor rock aquifers through the "skylights" of aquitards and the channels made in mining, such as abandoned holes and tunnels and then form shallow-to-deep cross strata pollution.

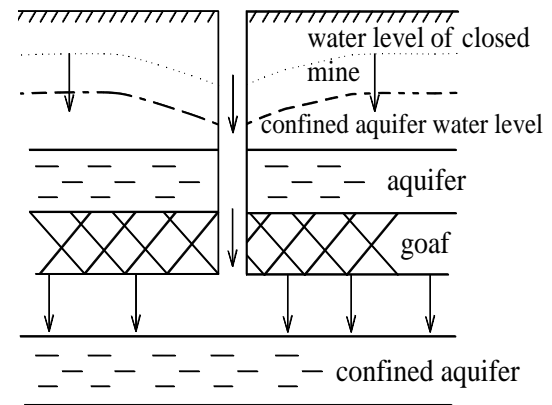

Fig. 1. "skylight"-type pollution.

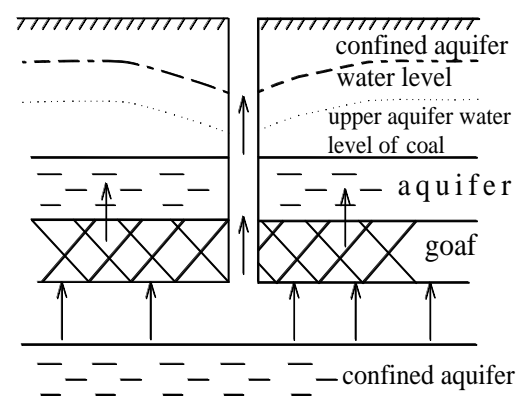

Fig. 2. Deep-to-shallow cross strata pollution.

The second is shown in Figure 2, when a mine is closed, the highly confined limestone aquifers at the bottom of the mine are polluted by the mine, because their hydraulic pressure is higher than the head values of the shallow aquifers, and the water goes into other aquifers with pollutants from a variety of man-made and natural channels and causes cross strata pollution from deep to 
shallow.

There has been some research on cross strata pollution, including the typical cases of Hongshan and Zhaili Coal Mine of Zibo Coal Mining Administration, which were closed in the 1990s and caused local groundwater pollution in some regions at the beginning of this century. Zhang Jianli et al. made analysis and concluded that the pollution course is cross strata pollution, and that the pollution of Ordovician limestone aquifers by mine drainage is diffuse and reflects the local characteristics of cross strata pollution, that is, the water in gob area pollutes karst water through a specific hydraulic contact.

\section{Prevention and Treatment of Mine Closure Water Pollution}

Groundwater pollution caused by mine closures has been already studied in the US, the UK, Russia and other countries as early as the 1980s, and a lot of tests and monitoring have been made. P.L. Younger [5],Burke [6], David Banks [7] et al. made much research on the laws of groundwater movement and simulations and built a variety of groundwater recharge models. Methods to treat mine closure pollutions fall into two categories: active treatment and passive treatment [8]. Due to the growing number of mine closures, China becomes aware of the importance of mine closure pollution control in recent years; China Coal Research Institute and China University of Mining and Technology have studied mine closure water pollution prevention and treatment and some viewpoints, such as "green closure" and reclamation of mine drainage, were proposed.

\subsection{Preventive measures before closure}

Most mine closure pollutions are caused by cross strata pollution. The control of cross strata pollution should be carried out from the following three aspects:

(1) Cutting off the pollution channels

Generally, the local anomaly watersheds in normal flow fields are the best blocking areas, and the contaminated mines in the watershed are the main blocking mines. The bad holes and shafts should be sealed through grouting to cut off the hydraulic connections between mine drainage and aquifers. Valid connectivity tests are required before sealing. In case of some most critical contaminated mines with twisted shaft walls, the original holes can be enlarged to the proposed depth, and hydraulic pressure tests should be made after sealing to check the blocking effect. In addition, full hole grouting of contaminated mines is not the only means of sealing. There is the possibility of secondary treatment, that is, secondary blocking, for many mines, so as to achieve the 
purpose of sealing and restoring a new well.

(2) Controlling flow fields

Cross strata pollutions occur when there is a great difference of water level in mine drainage and limestone water or karst water, so the control of groundwater flow fields can effectively control cross strata pollutions. Mine drainage level and karst water level should be controlled simultaneously, because it would be uneconomical to merely control one water level. The massive withdrawal of mine drainage should be combined with comprehensive utilization of mine drainage at this stage, such as irrigation or industrial use after treatment, to reduce the exploitation intensity of karst water.

\subsection{Treatment of contaminated mine groundwater}

Immediate appropriate treatment should be taken once the mine drainage involves contamination to minimize hazards. The treatment of mine drainage pollution falls into two categories:

(1) Pollutant treatment technologies

Treatment technologies differ from pollutants. The followings are treatment technologies for different pollutants:

It is difficult to remove suspended substances in mine drainage, which are mainly composed of dust and rock dust with a small diameter, relying merely on natural precipitation, and they must be removed with the addition of coagulant $\left(\mathrm{Al}_{2}\left(\mathrm{SO}_{4}\right)_{3}\right.$ and $\left.\mathrm{FeSO}_{4}\right)$ in a sedimentation tank by dispersing coagulant quickly and uniformly in water and causing reactions with and removing the aggregation of the colloidal impurities. For the mine drainage of low salinity and high suspended substance, the processes, such as coagulation, sedimentation, filtration and disinfection, are adopted to make the drainage achieve the national standard for productive water.

(2) Groundwater flow field control technology

It is to prevent further pollution of other aquifers by mine drainage through controlling groundwater flow fields. It includes two major methods:

I, Grouting for stopping water

It is to grout pollution channels with high quality cement to cut off the hydraulic connections between mine drainage and karst water and prevent further pollution of other aquifers by mine drainage[9].

II, Mine drainage recharging

It is a process of recharging the groundwater system with mine drainage after it is treated in the sewage treating system and reaches the standard.

This technology is applied in Wutongzhuang Coal Mine of Fengfeng Group. A water recharging system was built in Wutongzhuang Mine in 2008 to recharge groundwater with mine drainage, which contributes to the reduction of 
suspended substance emission amounting to $788.4 \mathrm{t}$ and salt emission to $40292.5 \mathrm{t}$ annually and realizes zero emission mines and great ecological efficiency.

\section{Conclusions}

Mine closures will lead to a series of Hydrogeological effects of the groundwater system. Some feasible and effective prevention means and preventive and treatment methods and the development trend of reclamation of mine closures are summarized in this paper based on the analysis and the study of the Hydrogeological effects, pollution principles and hazards and the previous study results made by other researchers. This paper is aimed at providing helpful references for the protection of the groundwater resource of mine closures.

\section{References}

1. Meisheng Feng.The study on Groundwater Pollution in Abandon Coal Mine.Thesis for degree: Liaoning Technical University,2006.(in Chinese)

2. Bo Gao. Groundwater Chemical Characteristics of JiaWang Coal Field in Response to Mine Closure. Thesis for degree: China University of Mining Technology,2014.(in Chinese)

3. Jianjun Zhou, Weiyue Hu. Analysis on rule of groundwater movement and model establishment of Current numerical simulation in abandoned mines.Journal of China coal society,2006,(31):70-73.(in Chinese)

4. $\mathrm{Pu}$ Liu,Yajun Sun.Discussion on Groundwater Pollution Caused by Abandoned Mines and its Controlling Techniques.Mining R\&D,Vol.31,No.4:91-95.(in Chinese)

5. P.L.Younger. Mine water pollution in Scotland:nature,extent and preventative strategies. The Science of the Total Environment, 265,(2001):309-326.

6. Adams R,Younger P.L.A strategy for modeling groundwater rebound in abandoned deep mine system.Ground Water,2001,39(2):249-261.

7. David Banks.A variable-volume, head-dependent mine water filling model.GroundWater,2001,39(3):362-365.

8. Christian Wolkerdorfer. Water Management at Abandoned Flooded Underground Mines.Leipzig(Germany):LE-TEX,2008:235-377.

9. Zhiming Li. Analysis of the super mineralized mine-water back-filling technology.China Coal,2010,11:111-113.(in Chinese) 